\title{
On mappings with $\varphi$-contractive iterate at a point on generalized metric spaces
}

\author{
Ljiljana Gajić ${ }^{1}$ and Mila Stojaković ${ }^{*}$
}

\author{
"Correspondence: stojakovic@sbb.rs \\ 2 Department of Mathematics, \\ Faculty of Technical Sciences, \\ University of Novi Sad, Novi Sad, \\ Serbia \\ Full list of author information is \\ available at the end of the article
}

\begin{abstract}
We prove a set of fixed point theorems for mappings with $\varphi$-contractive iterate at a point in a class of generalized metric spaces. This is a generalization of some well-known results for Guseman and Matkowski types of fixed point results in metric and generalized metric spaces.
\end{abstract}

MSC: $47 \mathrm{H} 10 ; 54 \mathrm{H} 25$

Keywords: $\varphi$-contraction; fixed point; mapping with contractive iterate at a point; generalized metric space

\section{Introduction and preliminaries}

In 1975 Matkowski introduced the following class of mappings.

Definition 1.1 [1] Let $T$ be a mapping on a metric space $(X, d)$. Then $T$ is called a weak contraction if there exists a function $\varphi$ from $[0, \infty)$ to itself satisfying the following:

(i) $\varphi$ is nondecreasing,

(ii) $\lim _{n} \varphi^{n}(t)=0$ for all $t>0$,

(iii) $d(T x, T y) \leq \varphi(d(x, y))$ for all $x, y \in X$.

In the same paper he proved the existence and uniqueness of a fixed point for such type of mappings. This result is significant because the concept of weak contraction of Matkowski type is independent of the Meir-Keeler contraction [2], and it was generalized in different directions [3-10]. Matkowski generalized his own result proving a theorem of Segal-Guseman type [11].

Theorem $1.1[4]$ Let $(X, d)$ be a complete metric space, $T: X \rightarrow X$, and $\varphi:[0, \infty) \rightarrow$ $[0, \infty)$. If $\varphi$ is nondecreasing, $\lim _{t \rightarrow \infty}(t-\varphi(t))=\infty, \lim _{k \rightarrow \infty} \varphi^{k}(t)=0$ for $t>0$, and for each $x \in X$ there is a positive integer $n=n(x)$ such that for all $y \in X$,

$$
d\left(T^{n(x)} x, T^{n(x)} y\right) \leq \varphi(d(x, y))
$$

then $T$ has a unique fixed point $a \in X$. Moreover, for each $x \in X, \lim _{k \rightarrow \infty} T^{k}(x)=a$.

The aim of this paper is to show that this result is valid in a more general class of spaces and wide class of functions $\varphi$.

In 1963, Gähler introduced 2-metric spaces, but other authors proved that there is no relation between the two distance functions and there is no easy relationship between re-

\section{照 Springer}

@2014 Gajić and Stojaković; licensee Springer. This is an Open Access article distributed under the terms of the Creative Commons Attribution License (http://creativecommons.org/licenses/by/2.0), which permits unrestricted use, distribution, and reproduction in any medium, provided the original work is properly cited. 
sults obtained in the two settings. Dhage introduced a new concept of the measure of nearness between three or more objects. But the topological structure of so-called $D$-metric spaces was incorrect. Finally, Mustafa and Sims [12] introduced the correct definition of a generalized metric space as follows.

Definition 1.2 [12] Let $X$ be a nonempty set, and let $G: X \times X \times X \rightarrow \mathbb{R}^{+}$be a function satisfying the following properties:

(G1) $G(x, y, z)=0$ if $x=y=z$;

(G2) $0<G(x, x, y)$, for all $x, y \in X$, with $x \neq y$;

(G3) $G(x, x, y) \leq G(x, y, z)$, for all $x, y, z \in X$, with $z \neq y$;

(G4) $G(x, y, z)=G(x, z, y)=G(y, z, x)=\cdots$ (symmetry in all three variables);

(G5) $G(x, y, z) \leq G(x, a, a)+G(a, y, z)$, for all $x, y, z, a \in X$.

Then the function $G$ is called a generalized metric, abbreviated $G$-metric, on $X$, and the pair $(X, G)$ is called a $G$-metric space.

Clearly these properties are satisfied when $G(x, y, z)$ is the perimeter of the triangle with vertices at $x, y$, and $z \in \mathbb{R}^{2}$. Moreover, taking $a$ in the interior of the triangle shows that (G5) is the best possible.

Example 1.1 [12] Let $(X, d)$ be an ordinary metric space, then $(X, d)$ defines $G$-metrics on $X$ by

$$
\begin{aligned}
& G_{s}(x, y, z)=d(x, y)+d(y, z)+d(x, z), \\
& G_{m}(x, y, z)=\max \{d(x, y), d(y, z), d(x, z)\} .
\end{aligned}
$$

Example 1.2 [12] Let $X=\{a, b\}$. Define $G$ on $X \times X \times X$ by

$$
G(a, a, a)=G(b, b, b)=0, \quad G(a, a, b)=1, \quad G(a, b, b)=2,
$$

and extend $G$ to $X \times X \times X$ by using the symmetry in the variables. Then it is clear that $(X, G)$ is a $G$-metric space.

The following useful properties of a G-metric are readily derived from the axioms.

Proposition 1.1 [12] Let $(X, G)$ be a G-metric space, then for any $x, y, z$ and a from $X$ it follows that:

1. if $G(x, y, z)=0$, then $x=y=z$,

2. $G(x, y, z) \leq G(x, x, y)+G(x, x, z)$,

3. $G(x, y, y) \leq 2 G(y, x, x)$,

4. $G(x, y, z) \leq G(x, a, z)+G(a, y, z)$

5. $G(x, y, z) \leq \frac{2}{3}(G(x, y, a)+G(x, a, z)+G(a, y, z))$,

6. $G(x, y, z) \leq G(x, a, a)+G(y, a, a)+G(z, a, a)$.

Definition 1.3 [12] Let $(X, G)$ be a $G$-metric space, and let $\left\{x_{n}\right\}$ be a sequence of points of $X$. A point $x \in X$ is said to be the limit of the sequence $\left\{x_{n}\right\}$ if $\lim _{n, m \rightarrow \infty} G\left(x, x_{n}, x_{m}\right)=0$, and one says that the sequence $\left\{x_{n}\right\}$ is G-convergent to $x$. 
Proposition 1.2 [12] Let $(X, G)$ be a G-metric space, then for a sequence $\left\{x_{n}\right\} \subseteq X$ and a point $x \in X$ the following are equivalent:

1. $\left\{x_{n}\right\}$ is G-convergent to $x$,

2. $G\left(x_{n}, x_{n}, x\right) \rightarrow 0$ as $n \rightarrow \infty$,

3. $G\left(x_{n}, x, x\right) \rightarrow 0$ as $n \rightarrow \infty$.

Definition 1.4 [12] Let $(X, G)$ be a $G$-metric space, a sequence $\left\{x_{n}\right\}$ is called G-Cauchy if for every $\varepsilon>0$, there is $N \in \mathbb{N}$ such that $G\left(x_{n}, x_{m}, x_{l}\right)<\varepsilon$, for all $n, m, l \geq N$, that is, if $G\left(x_{n}, x_{m}, x_{l}\right) \rightarrow 0$ as $n, m, l \rightarrow \infty$.

Proposition 1.3 [12] In a G-metric space $(X, G)$, the following are equivalent:

1. the sequence $\left\{x_{n}\right\}$ is G-Cauchy,

2. for every $\varepsilon>0$, there exists an $n_{0} \in \mathbb{N}$ such that $G\left(x_{n}, x_{m}, x_{m}\right)<\varepsilon$, for all $n, m \geq n_{0}$.

A $G$-metric space $(X, G)$ is $G$-complete (or complete $G$-metric), if every $G$-Cauchy sequence in $(X, G)$ is $G$-convergent in $(X, G)$.

Proposition 1.4 [12] Let $(X, G)$ be a G-metric space, then the function $G(x, y, z)$ is jointly continuous in all three of its variables.

Definition 1.5 $(X, G)$ is symmetric $G$-metric space if $G(x, y, y)=G(y, x, x)$ for all $x, y \in X$.

Fixed point theorems in symmetric G-metric space are mostly consequences of the related fixed point results in metric spaces. In this paper we discuss the non-symmetric case. In [13] it was shown that if $(X, G)$ is a $G$-metric space, putting $\delta(x, y)=G(x, y, y),(X, \delta)$ is a quasi-metric space ( $\delta$ is not symmetric). It is well known that any quasi-metric induces different metrics and mostly used are

( $\mu) \quad \mu(x, y)=\delta(x, y)+\delta(y, x)$

( $\rho) \quad \rho(x, y)=\max \{\delta(x, y), \delta(y, x)\}$.

The following result is an immediate consequence of above definitions and relations.

Theorem 1.2 Let $(X, G)$ be a G-metric space and let $D \in\{\delta, \rho\}$. Then

1. $\left\{x_{n}\right\} \subset X$ is G-convergent to $x \in X$ if and only if $\left\{x_{n}\right\}$ is convergent to $x$ in $(X, D)$;

2. $\left\{x_{n}\right\} \subset X$ is G-Cauchy if and only if $\left\{x_{n}\right\}$ is Cauchy in $(X, D)$;

3. $(X, G)$ is $G$-complete if and only if $(X, D)$ is complete.

Recently, Samet et al. [14] and Jleli-Samet [13] observed that some fixed point theorems in the context of a $G$-metric space can be proved (by simple transformation) using related existing results in the setting of a (quasi-) metric space. Namely, if the contraction condition of the fixed point theorem on $G$-metric space can be reduced to two variables, then one can construct an equivalent fixed point theorem in setting of usual metric space. This idea is not completely new, but it was not successfully used before (see [15]). Very recently, Karapinar and Agarwal suggest new contraction conditions in G-metric space in a way that the techniques in $[13,14]$ are not applicable. In this approach [16], contraction conditions cannot be expressed in two variables. So, in some cases, as is noticed even in Jleli-Samet's paper [13], when the contraction condition is of nonlinear type, this strategy cannot be always successfully used. This is exactly the case in our paper. 
For more fixed point results for mappings defined in $G$-metric spaces, we refer the reader to $[3,6,9,10,15-36]$.

\section{Main result}

A generalization of the contraction principle can be obtained using a different type of a nondecreasing function $\varphi:[0, \infty) \rightarrow[0, \infty)$. The most usual additional properties imposed on $\varphi$ are given using a combination of the next seven conditions:

$\left(\varphi_{1}\right) \varphi(0)=0$,

$\left(\varphi_{2}\right) \varphi(t)<t$, for all $t>0$,

$\left(\varphi_{3}\right) \lim _{i \rightarrow \infty} \varphi^{i}(t)=0$, for all $t>0$,

$\left(\varphi_{4}\right)$ if $\left\{t_{i}\right\} \subset[0, \infty)$ is a sequence such that $t_{i+1} \leq \varphi\left(t_{i}\right)$, then $\lim _{i \rightarrow \infty} t_{i}=0$,

$\left(\varphi_{5}\right)$ for any $y \geq 0$ there exists a $t(y) \geq 0, t(y)=\sup _{t \geq 0}\{t \leq y+\varphi(t)\}$,

$\left(\varphi_{6}\right) \lim _{t \rightarrow \infty}(t-\varphi(t))=\infty$,

$\left(\varphi_{7}\right) \sum_{i=1}^{\infty} \varphi^{i}(t)<\infty$, for all $t>0$.

Some of the noted properties of $\varphi$ are equivalent, some of them imply others, some of them are incompatible. The next lemma discusses some of the relations between properties $\left(\varphi_{1}\right)-\left(\varphi_{7}\right)$, especially those which are used in this paper to define a generalized contraction.

Lemma 2.1 Let $\varphi:[0, \infty) \rightarrow[0, \infty)$ be a nondecreasing function. Then

(i) $\left(\varphi_{3}\right) \Leftrightarrow\left(\varphi_{4}\right) \Rightarrow\left(\varphi_{2}\right)$,

(ii) if $\varphi$ is right continuous, then $\left(\varphi_{2}\right) \Leftrightarrow\left(\varphi_{3}\right) \Leftrightarrow\left(\varphi_{4}\right)$,

(iii) $\left(\varphi_{7}\right) \Rightarrow\left(\varphi_{k}\right) \Rightarrow\left(\varphi_{2}\right) \Rightarrow\left(\varphi_{1}\right)$, where $k \in\{3,4\}$,

(iv) $\left(\varphi_{5}\right) \Leftrightarrow\left(\varphi_{6}\right)$,

(v) $\left(\varphi_{2}\right) \nRightarrow\left(\varphi_{3}\right),\left(\varphi_{2}\right) \nRightarrow\left(\varphi_{4}\right)$,

(vi) $\left(\varphi_{5}\right)+\left(\varphi_{3}\right) \nRightarrow\left(\varphi_{7}\right)$ and $\left(\varphi_{6}\right)+\left(\varphi_{3}\right) \nRightarrow\left(\varphi_{7}\right)$,

(vii) $\left(\varphi_{7}\right) \nRightarrow\left(\varphi_{5}\right)$ and $\left(\varphi_{7}\right) \nRightarrow\left(\varphi_{6}\right)$.

Proof (i) $\left(\varphi_{3}\right) \Rightarrow\left(\varphi_{2}\right)$ : If for some $t>0, \varphi(t) \geq t$, then, knowing that $\varphi$ is nondecreasing, $\varphi^{i}(t) \geq \varphi^{i-1}(t) \geq \cdots \geq \varphi(t) \geq t>0$. It means that $\lim _{i \rightarrow \infty} \varphi^{i}(t) \neq 0$, which contradicts $\left(\varphi_{3}\right)$.

$\left(\varphi_{3}\right) \Rightarrow\left(\varphi_{4}\right)$ : Let $\left\{t_{i}\right\} \subset[0, \infty)$ be any sequence such that $t_{i+1} \leq \varphi\left(t_{i}\right)$. Using the implication $\left(\varphi_{3}\right) \Rightarrow\left(\varphi_{2}\right)$, we get $t_{i} \leq \varphi\left(t_{i-1}\right) \leq \varphi^{2}\left(t_{i-2}\right) \leq \cdots \leq \varphi^{i}\left(t_{0}\right)$ and $\lim _{i \rightarrow \infty} t_{i} \leq$ $\lim _{i \rightarrow \infty} \varphi^{i}\left(t_{0}\right)=0$.

$\left(\varphi_{4}\right) \Rightarrow\left(\varphi_{3}\right)$ : We assume that for some $t>0, \lim _{i \rightarrow \infty} \varphi^{i}(t)=a>0$. Since $\left(\varphi_{4}\right) \Rightarrow\left(\varphi_{2}\right)$, the sequence $t_{i}=\varphi^{i}(t)$ satisfies condition $t_{i+1}=\varphi^{i+1}(t)=\varphi\left(\varphi^{i}(t)\right) \leq \varphi^{i}(t)=t_{i}$, but it converges to $a>0$. That contradicts $\left(\varphi_{4}\right)$.

(ii) It is enough to prove that $\left(\varphi_{2}\right) \Rightarrow\left(\varphi_{3}\right)$ : We assume that for some $t>0, \lim _{i \rightarrow \infty} \varphi^{i}(t)=$ $a>0$. Since $\left\{\varphi^{i}(t)\right\}$ is a nonincreasing sequence, by the right continuity of $\varphi, \varphi(a)=$ $\varphi \lim _{i \rightarrow \infty} \varphi^{i}(t)=\lim _{i \rightarrow \infty} \varphi^{i+1}(t)=a>0$, i.e. $0<a=\varphi(a)$, which contradicts $\left(\varphi_{2}\right)$.

(iii), (iv) are obvious, so the proof is omitted.

(v) The function

$$
\varphi(t)= \begin{cases}\frac{t}{2}, & 0 \leq t \leq 2, \\ \frac{t}{2}+1, & 2<t\end{cases}
$$

satisfies $\left(\varphi_{2}\right)$, but not $\left(\varphi_{3}\right)$, nor $\left(\varphi_{4}\right)$, since for every $t>2, \lim _{i \rightarrow \infty} \varphi^{i}(t)=2 \neq 0$. 
(vi) The function

$$
\varphi(t)= \begin{cases}(n+2)^{-1}, & (n+1)^{-1} \leq t<n^{-1}, n \in \mathbb{N} \\ 3^{-1}, & 1 \leq t\end{cases}
$$

satisfies $\left(\varphi_{5}\right),\left(\varphi_{6}\right)$, and $\left(\varphi_{3}\right)$, but not $\left(\varphi_{7}\right)$.

(vii) The function

$$
\varphi(t)= \begin{cases}\left(\frac{t}{2}\right)^{2}, & 0 \leq t<2 \\ t-1, & 2 \leq t\end{cases}
$$

satisfies $\left(\varphi_{7}\right)$, but not $\left(\varphi_{5}\right)$, nor $\left(\varphi_{6}\right)$.

Theorem 2.1 Let $(X, G)$ be a complete $G$-metric space, $T: X \rightarrow X$, where the nondecreasing function $\varphi$ satisfies $\left(\varphi_{5}\right)$ or $\left(\varphi_{6}\right)$ together with $\left(\varphi_{3}\right)$ or $\left(\varphi_{4}\right)$ and for each $x \in X$ there exists a positive integer $n=n(x)$ such that

$$
G\left(T^{n(x)} x, T^{n(x)} x, T^{n(x)} y\right) \leq \varphi(G(x, x, y))
$$

for all $y \in X$. Then $T$ has a unique fixed point $a \in X$. Moreover, for each $x \in X, \lim _{k} T^{k} x=a$ and $T^{n(a)}$ is continuous at $a$.

Proof Let the nondecreasing function $\varphi$ satisfy $\left(\varphi_{6}\right)$ together with $\left(\varphi_{3}\right)$ (weak contraction in the sense of Matkowski). Then by Proposition 1.1(3), in a non-symmetric G-metric space we have

$$
G\left(T^{n(x)} x, T^{n(x)} y, T^{n(x)} y\right) \leq 2 G\left(T^{n(x)} x, T^{n(x)} x, T^{n(x)} y\right) \leq 2 \varphi(G(x, x, y)) .
$$

The last inequality together with (1) implies

$$
\rho\left(T^{n(x)} x, T^{n(x)} y\right) \leq 2 \varphi(\rho(x, y))
$$

for all $x, y \in X$. So, one can apply the Matkowski fixed point theorem if the function $2 \varphi=\tilde{\varphi}$ satisfies the conditions $\left(\varphi_{3}\right)$ and $\left(\varphi_{6}\right)$. Since there exist functions $\varphi$ which satisfy $\left(\varphi_{3}\right)$ and $\left(\varphi_{6}\right)$, but $2 \varphi$ does not (for example $\varphi(t)=\frac{t}{1+t}, t \geq 0$ ), the Jleli-Samet technique [13] is not applicable. We are going to prove our theorem using the $G$-metric $G$.

We first prove by mathematical induction that, for every $x \in X$, the orbit $\left\{T^{k} x\right\}_{k}$ is bounded.

Fix $x \in X$, fix the integer $s, 0 \leq s<n=n(x)$ and put

$$
\begin{aligned}
& u_{k}=G\left(x, x, T^{k n(x)+s} x\right), \quad k=0,1,2, \ldots, \\
& h=\max \left\{G\left(x, x, T^{n(x)} x\right), G\left(x, x, T x^{s}\right)\right\} .
\end{aligned}
$$

By $\left(\varphi_{6}\right)$ there exist $c, c>h$, such that

$$
t-\varphi(t)>h, \quad t>c .
$$


The last inequalities imply that $u_{0}<c$. Suppose that there exists a positive integer $j$ such that $u_{j} \geq c$, but $u_{i}<c$ for $i<j$.

Using (1), we get

$$
\begin{aligned}
u_{j} & =G\left(x, x, T^{j n(x)+s} x\right) \leq G\left(x, x, T^{n(x)} x\right)+G\left(T^{n(x)} x, T^{n(x)} x, T^{j n(x)+s} x\right) \\
& \leq h+\varphi\left(u_{j-1}\right) \leq h+\varphi\left(u_{j}\right),
\end{aligned}
$$

i.e. $u_{j}-\varphi\left(u_{j}\right) \leq h$, which contradicts the choice of $c$. Therefore $u_{j}<c$ for $j=0,1, \ldots$, and consequently the orbit $\left\{T^{k} x\right\}_{k}$ is bounded, so $\sup _{k} G\left(x, x, T^{k} x,\right)=M<\infty$.

For any $x_{0} \in X$, we define sequence $\left\{x_{k}\right\}_{k}$ as follows:

$$
x_{k+1}=T^{n_{k}} x_{k}, \quad n_{k}=n\left(x_{k}\right), k=0,1, \ldots
$$

We shall prove that $\left\{x_{k}\right\}_{k}$ is a Cauchy sequence. Let $k, j \in \mathbb{N}$. From (2) we obtain

$$
x_{k+j}=T^{n_{k+j-1}+\cdots+n_{k}} x_{k} .
$$

With the notation $s_{0}=n_{k+j-1}+\cdots+n_{k}$, we have

$$
\begin{aligned}
& G\left(x_{k}, x_{k}, x_{k+j}\right)=G\left(x_{k}, x_{k}, T^{s_{0}} x_{k}\right) \\
& =G\left(T^{n_{k-1}}\left(x_{k-1}\right), T^{n_{k-1}}\left(x_{k-1}\right), T^{n_{k-1}} T^{s 0} x_{k-1}\right) \\
& \leq \varphi\left(G\left(x_{k-1}, x_{k-1}, T^{s_{0}} x_{k-1}\right)\right) \leq \cdots \leq \varphi^{k}\left(G\left(x_{0}, x_{0}, T^{s_{0}} x_{0}\right)\right) \\
& \leq \varphi^{k}(M) \text {. }
\end{aligned}
$$

Since $\lim _{k} \varphi^{k}(t)=0,\left\{x_{k}\right\}_{k}$ is a Cauchy sequence in a complete $G$-metric space, $\lim _{k} x_{k}=a$, $a \in X$.

In order to prove that $T^{n(a)} a=a$, we assume that $G\left(a, T^{n(a)} a, T^{n(a)} a\right)=\varepsilon>0$. Using the same arguments as in the previous part of the proof, we see that

$$
\lim _{k} G\left(x_{k}, x_{k}, T^{n(a)} x_{k}\right)=0,
$$

meaning that there exists $k_{0} \in \mathbb{N}$ such that

$$
\lim _{k} G\left(x_{k}, x_{k}, T^{n(a)} x_{k}\right)<\frac{1}{8}(\varepsilon-\varphi(\varepsilon)), \quad G\left(a, a, x_{k}\right)<\frac{1}{8}(\varepsilon-\varphi(\varepsilon)) .
$$

Hence,

$$
\begin{aligned}
\varepsilon & =G\left(T^{n(a)} a, T^{n(a)} a, a\right) \\
& \leq G\left(T^{n(a)} a, T^{n(a)} a, T^{n(a)} x_{k}\right)+G\left(T^{n(a)} x_{k}, T^{n(a)} x_{k}, x_{k}\right)+G\left(x_{k}, x_{k}, a\right) \\
& \leq \varphi\left(G\left(a, a, x_{k}\right)\right)+\frac{1}{2}(\varepsilon-\varphi(\varepsilon))<\frac{1}{2}(\varepsilon+\varphi(\varepsilon))<\varepsilon .
\end{aligned}
$$

From the last contradiction we conclude that $T^{n(a)} a=a$. 
Suppose that there is a point $b \in X, b \neq a$, such that $T^{n(a)} b=b$. Then, by (1),

$$
G(a, a, b)=G\left(T^{n(a)} a, T^{n(a)} a, T^{n(a)} b\right) \leq \varphi(G(a, a, b))<G(a, a, b) .
$$

This contradiction proves that $a$ is a unique fixed point of $T^{n(a)}$. According to $T a=T^{n(a)} T a$ and from the uniqueness which has been proved already, we deduce that $T a=a$.

Next, we claim that $\lim _{k} T^{k} x=a$, for each $x \in X$. To prove this, fix $x \in X, s \in \mathbb{N}, 0 \leq s<$ $n(a)$ and put

$$
a_{k}=G\left(a, a, T^{k n(a)+s} x\right), \quad k=0,1,2, \ldots
$$

Then

$$
\begin{aligned}
a_{k} & =G\left(T^{n(a)} a, T^{n(a)} a, T^{n(a)} T^{(k-1) n(a)+s} x\right) \leq \varphi\left(G\left(a, a, T^{(k-1) n(a)+s} x\right)\right) \\
& =\varphi\left(a_{k-1}\right)<\cdots<\varphi^{k}\left(a_{0}\right) .
\end{aligned}
$$

By $\left(\varphi_{3}\right), \lim _{k} a_{k}=0$, which implies that $\lim _{k} T^{k} x=a$.

To prove continuity of $T^{n(a)}$ at $a$, we consider any sequence $\left\{y_{m}\right\}_{m} \subset X$ converging to $a$. For any $m \in \mathbb{N}$

$$
\begin{aligned}
G\left(a, a, T^{n(a)} y_{m}\right) & =G\left(T^{n(a)} a, T^{n(a)} a, T^{n(a)} y_{m}\right) \\
& \leq \varphi\left(G\left(a, a, y_{m}\right)\right)<G\left(a, a, y_{m}\right)
\end{aligned}
$$

for $y_{m} \neq a$. Letting $m \rightarrow \infty$, we get $\lim _{m} G\left(a, a, T^{n(a)} y_{m}\right)=0$. Hence, $\left\{T^{n(a)} y_{m}\right\}_{m}$ converges to $a=T^{n(a)} a$, meaning that $T^{n(a)}$ is continuous at $a$.

In other cases (when we use $\left(\varphi_{5}\right)$ instead of $\left(\varphi_{6}\right)$ or $\left(\varphi_{4}\right)$ instead of $\left(\varphi_{3}\right)$ ), by Lemma 2.1, the same conclusion can be drawn.

Corollary 2.1 Let $(X, G)$ be a complete G-metric space, $T: X \rightarrow X$ and for each $x \in X$ there exists a positive integer $n=n(x)$ such that

$$
G\left(T^{n(x)} x, T^{n(x)} x, T^{n(x)} y\right) \leq q G(x, x, y)
$$

for all $y \in X$ and some $q \in(0,1)$. Then $T$ has a unique fixed point $a \in X$. Moreover, for each $x \in X, \lim _{k} T^{k} x=a$ and $T^{n(a)}$ is continuous at $a$.

Proof The function $\varphi(t)=q \cdot t, t \in[0, \infty)$, satisfies $\left(\varphi_{3}\right)$ and $\left(\varphi_{6}\right)$, so the corollary is a consequence of Theorem 2.1.

From the proof of Theorem 2.1 we can see that it would be enough to impose certain assumptions not for all elements from $X$ but only over some subset $B$ of $X$, just as was done by Guseman [11]. The next theorem is a Guseman type of fixed point theorem in a G-metric space.

Theorem 2.2 Let $T$ be a selfmapping of a complete G-metric space $(X, G)$. If there exists a subset $B$ of $X$ such that $T(B) \subseteq B, T$ satisfies (1) over $B$ and for some $x_{0} \in X, \overline{\left\{T^{n} x_{0}: n \geq 0\right\}} \subseteq$ 
$B$, then there exists a unique $u \in B$ such that $T u=u$ and $\lim _{k \rightarrow \infty} T^{k} y=u$ for each $y \in B$. Furthermore, if $T$ satisfies (1) over $X$, then $u$ is unique fixed point in $X$ and $\lim _{k \rightarrow \infty} T^{k} y=u$ for each $y \in X$.

Remark 2.1 Taking $\varphi(t)=q \cdot t, 0<q<1$, by Theorem 2.2 we obtain the fixed point result from [23] or [24], so Theorem 2.2 is also a generalization of the Guseman fixed point result from [11].

Corollary 2.2 Let $(X, G)$ be a complete G-metric space, $T: X \rightarrow X$, and for each $x \in X$ there exists a positive integer $n=n(x)$ such that

$$
G\left(T^{n(x)} x, T^{n(x)} x, T^{n(x)} y\right) \leq \frac{G(x, x, y)}{1+G(x, x, y)}
$$

for all $y \in X$. Then $T$ has a unique fixed point $a \in X$. Moreover, for each $x \in X, \lim _{k} T^{k} x=a$ and $T^{n(a)}$ is continuous at a.

Proof Since the function $\varphi(t)=\frac{t}{1+t}, t \in[0, \infty)$, satisfies $\left(\varphi_{3}\right),\left(\varphi_{4}\right),\left(\varphi_{5}\right)$, and $\left(\varphi_{6}\right)$, we can apply Theorem 2.1. Also for that $\varphi$, the appropriate version of Theorem 2.2 can be formulated in a similar way as was done in this corollary.

If $n(x)=m \in \mathbb{N}$, for each $x \in X$, it is easy to see that condition $\left(\varphi_{5}\right)$ or $\left(\varphi_{6}\right)$ in Theorem 2.1 can be omitted. This version of Theorem 1.2 is an improvement and another proof of Theorem 3.1 (Corollary 3.2) from [9]. But in that case it would be more appropriate to use the metric $\rho$, which reduces (1) to $\rho\left(T^{m} x, T^{m} y\right) \leq \varphi(\rho(x, y)), x, y \in X$ and enables the use of well-known results in metric spaces.

Proposition 2.1 Let $(X, G)$ be a complete $G$-metric space, where $\varphi$ is a nondecreasing function satisfying $\left(\varphi_{3}\right)$. If $T: X \rightarrow X$ satisfies

$$
G\left(T^{m} x, T^{m} x, T^{m} y\right) \leq \varphi(G(x, x, y))
$$

for all $x, y \in X$ and some $m \in \mathbb{N}$, then $T$ has a unique fixed point $a \in X$. Moreover, for each $x \in X, \lim _{k} T^{k} x=a$ and $T^{n(a)}$ is continuous at $a$.

The next theorem is also a Guseman type of fixed point theorem in a G-metric space. The assumptions about the contractor $\varphi$ is different with respect to Theorem 2.2. Similarly as in previous analysis, the next theorem can be applied in a metric space and in cases where some special form of function $\varphi$ is used.

Theorem 2.3 Let $f: X \rightarrow X$, where $(X, G)$ is a G-metric space and let $\varphi:[0, \infty) \rightarrow[0, \infty)$ be a subadditive mapping satisfying $\left(\varphi_{7}\right)$. If for some $x_{0} \in X$ the closure of orbit $\overline{\mathcal{O}\left(f ; x_{0}\right)}$ is complete and for each $x \in \mathcal{O}\left(f ; x_{0}\right)$ there exists an $n(x) \in \mathbb{N}$ such that

$$
G\left(f^{n(x)} y, f^{n(x)} x, f^{n(x)} x\right) \leq \varphi(G(y, x, x))
$$

for all $y \in \mathcal{O}\left(f ; x_{0}\right)$, then the sequence $x_{i+1}=f^{n\left(x_{i}\right)} x_{i}, i \in \mathbb{N}_{0}$, converges to some $x^{*} \in X$.

If inequality (4) holds for all $x \in \overline{\mathcal{O}\left(f ; x_{0}\right)}$, then $f^{n\left(x^{*}\right)} x^{*}=x^{*}$ and $\lim _{i} f^{i}(x)=x^{*}$ for every $x \in \overline{\mathcal{O}\left(f ; x_{0}\right)}$. If $\overline{\left(\mathcal{O}\left(f ; x_{0}\right)\right)} \subseteq \overline{\mathcal{O}\left(f ; x_{0}\right)}$, then $x^{*}$ is a fixed point off . 
Proof First, we show that $\left\{x_{i}\right\}_{i \in \mathbb{N}_{0}} \subset X$ is a Cauchy sequence. For sufficiently large $m \in \mathbb{N}$, there exist $k, r \in \mathbb{N}, 1 \leq r<n\left(x_{0}\right)$ such that $m=k \cdot n\left(x_{0}\right)+r$. Using (4), we get

$$
\begin{aligned}
& G\left(f^{m} x_{0}, x_{0}, x_{0}\right) \\
& \leq G\left(f^{k n\left(x_{0}\right)+r} x_{0}, f^{n\left(x_{0}\right)} x_{0}, f^{n(x)_{0}} x_{0}\right)+G\left(f^{n\left(x_{0}\right)} x_{0}, x_{0}, x_{0}\right) \\
& \leq \varphi\left(G\left(f^{(k-1) n\left(x_{0}\right)+r} x_{0}, x_{0}, x_{0}\right)\right)+G\left(f^{n\left(x_{0}\right)} x_{0}, x_{0}, x_{0}\right) \\
& \leq \varphi\left(G\left(f^{(k-1) n\left(x_{0}\right)+r} x_{0}, f^{n\left(x_{0}\right)} x_{0}, f^{n} x_{0}\right)\right. \\
&\left.+G\left(f^{n\left(x_{0}\right)} x_{0}, x_{0}, x_{0}\right)\right)+G\left(f^{n\left(x_{0}\right)} x_{0}, x_{0}, x_{0}\right) \\
& \leq \varphi^{2}\left(G\left(f^{(k-2) n\left(x_{0}\right)+r} x_{0}, x_{0}, x_{0}\right)\right) \\
&+\varphi\left(G\left(f^{n\left(x_{0}\right)} x_{0}, x_{0}, x_{0}\right)\right)+G\left(f^{n\left(x_{0}\right)} x_{0}, x_{0}, x_{0}\right) \leq \cdots \\
& \leq \varphi^{k}\left(G\left(f^{r} x_{0}, x_{0}, x_{0}\right)\right)+\sum_{i=0}^{k-1} \varphi^{i}\left(G\left(f^{n\left(x_{0}\right)} x_{0}, x_{0}, x_{0}\right)\right) .
\end{aligned}
$$

Putting $A=\max \left\{G\left(f^{p} x_{0}, x_{0}, x_{0}\right): 1 \leq p \leq n\left(x_{0}\right)\right\}$, for all $m \in \mathbb{N}$, the next inequality holds:

$$
G\left(f^{m} x_{0}, x_{0}, x_{0}\right) \leq \sum_{s=0}^{k} \varphi^{s}(A) \leq \sum_{s=0}^{\infty} \varphi^{s}(A)=B<\infty
$$

and consequently,

$$
\begin{aligned}
G\left(x_{m}, x_{m}, x_{m+1}\right) & =G\left(f^{n\left(x_{m-1}\right)} x_{m-1}, f^{n\left(x_{m-1}\right)} x_{m-1}, f^{n\left(x_{m}\right)} f^{n\left(x_{m-1}\right)} x_{m-1}\right) \\
& \leq \varphi\left(G\left(x_{m-1}, x_{m-1}, f^{n\left(x_{m}\right)} x_{m-1}\right)\right) \leq \cdots \\
& \leq \varphi^{m}\left(G\left(x_{0}, x_{0}, f^{n\left(x_{m}\right)} x_{0}\right)\right) \leq \varphi^{m}(B)
\end{aligned}
$$

for all $m \in \mathbb{N}$. Using the last inequality, for every $i, j \in \mathbb{N}, i<j$, we have

$$
G\left(x_{i}, x_{i}, x_{j}\right) \leq G\left(x_{i}, x_{i}, x_{i+1}\right)+\cdots+G\left(x_{k-1}, x_{k-1}, x_{k}\right) \leq \sum_{s=i}^{j} \varphi^{s}(B)
$$

implying that $\left\{x_{i}\right\}_{i \in \mathbb{N}}$ is a Cauchy sequence. Since $\overline{\mathcal{O}\left(f ; x_{0}\right)}$ is complete, and there exists an $x^{*} \in \overline{\mathcal{O}\left(f ; x_{0}\right)}$ such that $\lim _{i \rightarrow \infty} x_{i}=x^{*}$.

In the second part of the theorem, inequality (4) holds for all $x \in \overline{\mathcal{O}\left(f ; x_{0}\right)}$. Then the elements $x_{i}$ of the sequence $\left\{x_{i}\right\}_{i \in \mathbb{N}}$ from the previous part of the proof satisfy the next two relations:

$$
G\left(f^{n\left(x^{*}\right)} x^{*}, f^{n\left(x^{*}\right)} x^{*}, f^{n\left(x^{*}\right)} x_{i}\right) \leq \varphi\left(G\left(x^{*}, x^{*}, x_{i}\right)\right)<G\left(x^{*}, x^{*}, x_{i}\right)
$$

and

$$
\begin{aligned}
G\left(f^{n\left(x^{*}\right)} x_{i}, x_{i}, x_{i}\right) & =G\left(f^{n\left(x^{*}\right)} f^{n\left(x_{i-1}\right)} x_{i-1}, f^{n\left(x_{i-1}\right)} x_{i-1}, f^{n\left(x_{i-1}\right)} x_{i-1}\right) \\
& \leq \varphi\left(G\left(f^{n\left(x^{*}\right)} x_{i-1}, x_{i-1}, x_{i-1}\right)\right) \leq \varphi^{i}\left(G\left(f^{n\left(x^{*}\right)} x_{0}, x_{0}, x_{0}\right)\right) .
\end{aligned}
$$


By (6)

$$
\lim _{i \rightarrow \infty} f^{n\left(x^{*}\right)} x_{i}=f^{n\left(x^{*}\right)} x^{*}
$$

and by (7)

$$
\lim _{i \rightarrow \infty} G\left(f^{n\left(x^{*}\right)} x_{i}, x_{i}, x_{i}\right)=G\left(f^{n\left(x^{*}\right)} x^{*}, x^{*}, x^{*}\right)=0 .
$$

Hence, $f^{n\left(x^{*}\right)} x^{*}=x^{*}$.

Next, we claim that $\lim _{k} f^{i} x=x^{*}$, for each $x \in \overline{\mathcal{O}\left(f ; x_{0}\right)}$. Putting $i=k n\left(x^{*}\right)+s, s \in \mathbb{N}, 0 \leq$ $s<n\left(x^{*}\right)$, we get

$$
\begin{aligned}
G\left(f^{k n(m z)+s} x, x^{*}, x^{*}\right) & \leq \varphi\left(G\left(f^{(k-1) n(m z)+s} x, x^{*}, x^{*}\right)\right) \leq \cdots \\
& \leq \varphi^{k}\left(G\left(f^{s} x, x^{*}, x^{*}\right)\right)=\varphi^{k}(M)
\end{aligned}
$$

where $M=\max \left\{G\left(f^{s} x, x^{*}, x^{*}\right): 0 \leq s<n\left(x^{*}\right)\right\}$. Since $\left(\varphi_{7}\right) \Rightarrow\left(\varphi_{3}\right), \lim _{k} f^{i} x=x^{*}$.

To show that $x^{*}$ is a unique fixed point of $f^{n\left(x^{*}\right)}$ in $\overline{\mathcal{O}\left(f ; x_{0}\right)}$, we assume that there exists another point $x^{* *} \in \overline{\mathcal{O}\left(f ; x_{0}\right)}$ with the same property. Then

$$
G\left(x^{* *}, x^{*}, x^{*}\right)=G\left(f^{n\left(x^{*}\right)} x^{* *}, f^{n\left(x^{*}\right)} x^{*}, f^{n\left(x^{*}\right)} x^{*}\right) \leq \varphi\left(G\left(x^{* *}, x^{*}, x^{*}\right)\right),
$$

that is, $x^{* *}=x^{*}$. Further, if $\overline{f\left(\mathcal{O}\left(f ; x_{0}\right)\right)} \subseteq \overline{\mathcal{O}\left(f ; x_{0}\right)}$, then $f x^{*}=f\left(f^{n\left(x^{*}\right)} x^{*}\right)=f^{n\left(x^{*}\right)}\left(f x^{*}\right)$, implying $f x^{*}=x^{*}$.

In the last theorem in this paper we consider a common fixed point for a family of selfmappings with the property of a contractive iterate at a point. The generalized contractive condition is imposed over a subset of a G-metric space.

Theorem 2.4 Let $(X, G)$ be G-metric space and $B \subseteq X$. Further, let $\left\{f_{i}\right\}$ be the sequence of selfmappings of $X$ such that for all $i \in \mathbb{N}, f_{i}(B) \subseteq B$ and for each $x \in X$ there exists an $n(x) \in \mathbb{N}$ such that

$$
\begin{aligned}
G\left(f_{i}^{n(x)} y, f_{j}^{n(x)} x, f_{j}^{n(x)} x\right) \leq & \varphi\left(\operatorname { m a x } \left\{G(y, x, x), G\left(y, f_{j}^{n(x)} x, f_{j}^{n(x)} x\right), G\left(x, f_{j}^{n(x)} x, f_{j}^{n(x)} x\right),\right.\right. \\
& \left.\left.2^{-1}\left[G\left(y, f_{i}^{n(x)} x, f_{i}^{n(x)} x\right)+G\left(f_{i}^{n(x)} y, x, x\right)\right]\right\}\right)
\end{aligned}
$$

for all $i, j \in \mathbb{N}, i \neq j$, and all $y \in B$, where $\varphi:[0, \infty) \rightarrow[0, \infty)$ is a nondecreasing right continuous function satisfying $\left(\varphi_{2}\right)$. If there exists $x^{*} \in B$ such that $f_{i}^{n\left(x^{*}\right)}\left(x^{*}\right)=x^{*}$ for all $i \in \mathbb{N}$, then $x^{*}$ is a unique common fixed point for $\left\{f_{i}\right\}$ in $B$ and for every $x_{1} \in B$, the sequence $x_{i+1}=f_{i}^{n\left(x^{*}\right)}\left(x_{i}\right), i \in \mathbb{N}$, converges to $x^{*}$.

Proof First we prove that $x^{*}$ is a unique point in $B$ with the property that $f_{i}^{n\left(x^{*}\right)} x^{*}=x^{*}$, $i \in \mathbb{N}$. If $x^{* *} \in B, x^{* *} \neq x^{*}, f_{i}^{n\left(x^{*}\right)} x^{* *}=x^{* *}, i \in \mathbb{N}$, then

$$
G\left(x^{* *}, x^{*}, x^{*}\right) \leq G\left(f_{i}^{n\left(x^{*}\right)} x^{* *}, f_{j}^{n\left(x^{*}\right)} x^{*}, f_{j}^{n\left(x^{*}\right)} x^{*}\right) \leq \varphi\left(G\left(x^{* *}, x^{*}, x^{*}\right)\right) .
$$

By $\varphi(t)<t, t>0$, since $G\left(x^{* *}, x^{*}, x^{*}\right)>0$, we have a contradiction, that is, the assumption $x^{*} \neq x^{* *}$ is not correct. 
Further, since

$$
f_{i}\left(x^{*}\right)=f_{i}\left(f_{i}^{n\left(x^{*}\right)} x^{*}\right)=f_{i}^{n\left(x^{*}\right)+1} x^{*}=f_{i}^{n\left(x^{*}\right)}\left(f_{i} x^{*}\right),
$$

it follows that $f_{i} x^{*}=x^{*}$ for all $i \in \mathbb{N}$.

Now, for some $x_{1} \in B$, we form the sequence $x_{i+1}=f_{i}^{n\left(x^{*}\right)} x_{i}$.

If $x_{1}=x^{*}$, then $x_{i}=f_{i-1}^{n\left(x^{*}\right)}\left(f_{i-2}^{n\left(x^{*}\right)} \cdots\left(f_{1}^{n\left(x^{*}\right)} x^{*}\right) \cdots\right)=x^{*}$ and the sequence $\left\{x_{i}\right\}$ converges to $x^{*}$.

If $x_{i} \neq x^{*}$, in order to prove that the sequence $\left\{x_{i}\right\}$ converges to $x^{*}$, we consider the sequence $G\left(x_{i+1}, x^{*}, x^{*}\right), i \in \mathbb{N}$,

$$
\begin{aligned}
G\left(x_{i+1}, x^{*}, x^{*}\right)= & G\left(f_{i}^{n\left(x^{*}\right)} x_{i}, f_{j}^{n\left(x^{*}\right)} x^{*}, f_{j}^{n\left(x^{*}\right)} x^{*}\right) \\
\leq & \varphi\left(\operatorname { m a x } \left\{G\left(x_{i}, x^{*}, x^{*}\right), G\left(x_{i}, x^{*}, x^{*}\right), G\left(x^{*}, x^{*}, x^{*}\right),\right.\right. \\
& \left.\left.2^{-1}\left[G\left(x_{i}, x^{*}, x^{*}\right)+G\left(x_{i+1}, x^{*}, x^{*}\right)\right]\right\}\right) \\
= & \varphi\left(\max \left\{G\left(x_{i}, x^{*}, x^{*}\right), 2^{-1}\left[G\left(x_{i}, x^{*}, x^{*}\right)+G\left(x_{i+1}, x^{*}, x^{*}\right)\right]\right\}\right) .
\end{aligned}
$$

If we choose the option that

$$
\begin{aligned}
& \max \left\{G\left(x_{i}, x^{*}, x^{*}\right), 2^{-1}\left[G\left(x_{i}, x^{*}, x^{*}\right)+G\left(x_{i+1}, x^{*}, x^{*}\right)\right]\right\} \\
& =2^{-1}\left[G\left(x_{i}, x^{*}, x^{*}\right)+G\left(x_{i+1}, x^{*}, x^{*}\right)\right],
\end{aligned}
$$

it implies that

$$
G\left(x_{i}, x^{*}, x^{*}\right) \leq G\left(x_{i+1}, x^{*}, x^{*}\right) .
$$

On the other hand, in that case

$$
\begin{aligned}
G\left(x_{i+1}, x^{*}, x^{*}\right) & \leq \varphi\left(2^{-1}\left[G\left(x_{i}, x^{*}, x^{*}\right)+G\left(x_{i+1}, x^{*}, x^{*}\right)\right]\right) \\
& <2^{-1} G\left(x_{i}, x^{*}, x^{*}\right)+2^{-1} G\left(x_{i+1}, x^{*}, x^{*}\right),
\end{aligned}
$$

that is,

$$
G\left(x_{i+1}, x^{*}, x^{*}\right)<G\left(x_{i}, x^{*}, x^{*}\right) .
$$

It is obvious that (9) contradicts (10). So,

$$
G\left(x_{i+1}, x^{*}, x^{*}\right) \leq \varphi\left(G\left(x_{i}, x^{*}, x^{*}\right)\right) .
$$

Now, applying that procedure $i$ times and letting $i \rightarrow \infty$, we get

$$
G\left(x_{i+1}, x^{*}, x^{*}\right) \leq \varphi\left(G\left(x_{i}, x^{*}, x^{*}\right)\right) \leq \cdots \leq \varphi^{i}\left(G\left(x_{1}, x^{*}, x^{*}\right)\right) .
$$

Since $x_{1} \neq x^{*}, G\left(x_{i}, x^{*}, x^{*}\right)>0$ and $\lim _{i \rightarrow \infty} G\left(x_{i+1}, x^{*}, x^{*}\right)=0$. The last relation proves that the sequence $\left\{x_{i}\right\}$ converges to $x^{*}$. 
Authors' contributions

Both authors have equal contribution in the paper and they read and approved the final manuscript.

\section{Author details}

${ }^{1}$ Department of Mathematics and Informatics, Faculty of Science, University of Novi Sad, Novi Sad, Serbia. ${ }^{2}$ Department of Mathematics, Faculty of Technical Sciences, University of Novi Sad, Novi Sad, Serbia.

\section{Acknowledgements}

The authors are very grateful to the anonymous referees for their careful reading of the paper and suggestions, which have contributed to the improvement of the paper. This work is supported by Ministry of Science and Technological Development, Republic of Serbia.

\section{Received: 18 July 2013 Accepted: 6 February 2014 Published: 21 Feb 2014}

\section{References}

1. Matkowski, J: Integrable Solutions of Functional Equations. Diss. Math., vol. 127. Panstwowe Wydawnictwo Naukove, Warsaw (1975)

2. Meir, A, Keeler, E: A theorem on contraction mappings. J. Math. Anal. Appl. 28, 326-329 (1969)

3. Aage, CT, Salunke, JN: Fixed point for weak contraction in G-metric spaces. Appl. Math. E-Notes 12, $23-28$ (2012)

4. Matkowski, J: Fixed point theorems for mappings with a contractive iterate at a point. Proc. Am. Math. Soc. 62, 344-348 (1997)

5. Matkowski, J: Fixed point theorems for contractive mappings in metric spaces. Čas. Pěst. Mat. 105, 341-344 (1980)

6. Rao, KP, Lakshni, KB, Mustafa, Z: A unique common fixed point theorem for six maps in G-metric spaces. Int. J. Nonlinear Anal. Appl. 2 (2011)

7. Reich, S, Zaslavski, AJ: A fixed point theorem for Matkowski contractions. Fixed Point Theory 8, 303-307 (2007)

8. Romaguera, S: Matkowski's type theorems for generalized contractions on (ordered) partial metric spaces. Appl. Gen. Topol. 12(2), 213-220 (2011)

9. Shatanawi, W: Fixed point theory for contractive mappings satisfying $\Phi$-maps in G-metric spaces. Fixed Point Theory Appl. 2010, Article ID 181650 (2010)

10. Suzuki, T, Vetro, C: Three existence theorems for weak contraction of Matkowski type. Int. J. Math. Stat. 6, 110-120 (2010).

11. Guseman, LF: Fixed point theorems for mappings with a contractive iterate at a point. Proc. Am. Math. Soc. 26 615-618 (1970)

12. Mustafa, Z, Sims, B: A new approach to generalized metric spaces. J. Nonlinear Convex Anal. 7(2), 289-297 (2006)

13. Jleli, M, Samet, B: Remarks on G-metric spaces and fixed point theorems. Fixed Point Theory Appl. 2012,210 (2012). doi:10.1186/1687-1812-2012-210

14. Samet, B, Vetro, C, Vetro, F: Remarks on G-metric spaces. Int. J. Anal. 2013, Article ID 917158 (2013)

15. Mustafa, Z, Obiedat, H, Awawdeh, H: Some fixed point theorem for mappings on complete G-metric spaces. Fixed Point Theory Appl. 2008, Article ID 189870 (2008)

16. Karapinar, E, Agarval, R: Further remarks on G-metric spaces. Fixed Point Theory Appl. 2013, 154 (2013). doi:10.1186/1687-1812-2013-154

17. Abbas, M, Rhoades, BE: Common fixed point results for noncommuting mapping without continuity in generalized metric space. Appl. Math. Comput. 215, 262-269 (2009)

18. Agarwal, R, Karapinar, E: Remarks on some coupled fixed point theorems in G-metric spaces. Fixed Point Theory Appl. 2013, 21 (2013)

19. Aydi, H, Karapinar, E, Shatanawi, W: Tripled common fixed point results for generalized contractions in ordered generalized metric spaces. Fixed Point Theory Appl. 2012, 101 (2012)

20. Aydi, H, Karapinar, E, Shatanawi, W: Tripled fixed point results in generalized metric spaces. J. Appl. Math. 2012, Article ID $314279(2012)$

21. Aydi, H, Shatanawi, W, Vetro, C: On generalized weakly G-contraction mapping in G-metric spaces. Comput. Math. Appl. 62, 4222-4229 (2011)

22. Chugh, R, Kadian, T, Rani, A, Rhoades, BE: Property P in G-metric spaces. Fixed Point Theory Appl. 2010, Article ID $401684(2010)$

23. Gajić, L, Lozanov-Crvenković, Z: On mappings with contractive iterate at a point in generalized metric spaces. Fixed Point Theory Appl. 2010, Article ID 458086 (2010). doi:10.1155/2010/458086

24. Gajić, L, Lozanov-Crvenković, Z: A fixed point result for mappings with contractive iterate at a point in G-metric spaces. Filomat 25(2), 53-58 (2011)

25. Gajić, L, Stojaković, M: On Ćirić generalization of mappings with a contractive iterate at a point in G-metric space. Appl. Math. Comput. 219, 435-441 (2012)

26. Gholizadeh, L, Saadati, R, Shatanawi, W, Vaezpour, SM: Contractive mapping in generalized, ordered metric spaces with application in integral equations. Math. Probl. Eng. 2011, Article ID 380784 (2011). doi:10.1155/2011/380784

27. Mustafa, Z, Shatanawi, W, Bataneih, M: Existence of fixed point results in G-metric spaces. Int. J. Math. Math. Sci. 2009, Article ID 283028 (2009). doi:10.1155/2009/283028

28. Mustafa, Z, Shatanawi, W, Bataneih, M: Fixed point theorem on uncomplete G-metric spaces. J. Math. Stat. 4(4), $196-210(2008)$

29. Mustafa, Z, Sims, B: Fixed point theorems for contractive mappings in complete G-metric spaces. Fixed Point Theory Appl. 2009, Article ID 917175 (2009)

30. Mustafa, Z, Aydi, H, Karapinar, E: On common fixed points in G-metric spaces using (E.A) property. Comput. Math. Appl. (2012). doi:10.1016/j.camwa.2012.03.051

31. Mustafa, Z, Aydi, H, Karapinar, E: Mixed $g$-monotone property and quadruple fixed point theorems in partially ordered metric space. Fixed Point Theory Appl. 2012, 71 (2012)

32. Mustafa, Z, Khandaqji, M, Shatanawi, W: Fixed point results on complete G-metric spaces. Studia Sci. Math. Hung. 48(3), 304-319 (2011) 
33. Shatanawi, W, Postolache, M: Some fixed point results for a G-weak contraction in G-metric spaces. Abstr. Appl. Anal. 2012, Article ID 815870 (2012). doi:10.1155/2012/815870

34. Shatanawi, W: Some fixed point theorems in ordered G-metric spaces and applications. Abstr. Appl. Anal. 2011, Article ID 126205 (2011). doi:10.1155/2011/126205

35. Tahat, N, Aydi, H, Karapinar, E, Shatanawi, W: Common fixed points for single-valued and multi-valued maps satisfying a generalized contraction in G-metric spaces. Fixed Point Theory Appl. 2012, 48 (2012). doi:10.1186/1687-1812-2012-48

36. An, TV, Dung, NV, Hang, VTL: A new approach to fixed point theorems on G-metric spaces. Topol. Appl. 160(12), 1486-1493 (2013)

10.1186/1687-1812-2014-46

Cite this article as: Gajić and Stojaković: On mappings with $\varphi$-contractive iterate at a point on generalized metric spaces. Fixed Point Theory and Applications 2014, 2014:46

Submit your manuscript to a SpringerOpen ${ }^{\odot}$ journal and benefit from:

- Convenient online submission

- Rigorous peer review

- Immediate publication on acceptance

- Open access: articles freely available online

- High visibility within the field

- Retaining the copyright to your article

Submit your next manuscript at $>$ springeropen.com 